\title{
Tsunami Monitoring by HF Ocean Radar: Time and Space Scales
}

\author{
Heron, M.L. \\ James Cook Univ., Townsville; \\ This paper appears in: OCEANS 2007 - Europe \\ Publication Date: 18-21 June 2007 \\ On page(s): $1-5$ \\ ISBN: 978-1-4244-0635-7 \\ INSPEC Accession Number: 9796317 \\ DOI: $10.1109 /$ OCEANSE.2007.4302278 \\ Posted online: 2007-09-17 09:36:27.0
}

\begin{abstract}
HF coastal ocean radars are ideal instruments for detection of surface currents in coastal waters and have had wide application for monitoring tidal and wind driven surface currents. This paper addresses the questions of spatial and temporal scales for optimal detection of tsunami properties by HF radar at the shelf break and on the continental shelf itself. Two approaches are used in this evaluation. One is a stylized tsunami wave approaching a shelf which has parallel bathymetry contours and a shelf with uniform depth. In this case the non-linear effects at the edge of the shelf are the same at all points along the shelf edge, and the subsequent wave train emerging onto the shelf has parallel wave fronts. The second approach is a case study of a real section of shelf-edge and shelf bathymetry. In this case numerical modelling indicates that there is a complex pattern of surface currents at the shelf break which varies in space and time. The subsequent wave train has a complex wave front which can be considered to be generated from point sources along the shelf edge. These wave fronts are shaped by local shelf bathymetry as well as interference of waves from the originating source points at the shelf edge. In the case of real bathymetry there are complexities in the surface current field which will produce different outcomes for direction-finding and phased array types of HF radar facilities. Because of its ability to resolve spatially complex current patterns, the phased array system is preferred for tsunami observation networks.
\end{abstract}

Index Terms

Available to subscribers and IEEE members.

References

Avallable to subscribers and IEEE members.

Citing Documents

Available to subscribers and IEEE members.

Indexted

Winspec 